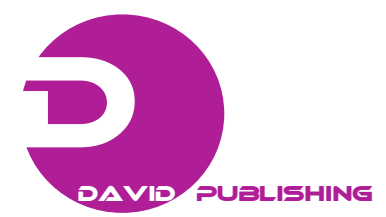

\title{
Empowering Rural Women for Food and Nutrition
}

\author{
Ferdouse Islam \\ Olericulture Division, Horticulture Research Centre Bangladesh Agricultural Research Institute (BARI), Gazipur 1701, Bangladesh \\ Corresponding author's e-mail: ive_bari@yahoo.com
}

\begin{abstract}
Empowering women has multiple benefits for women themselves and for their families and communities. To economic condition of Bangladesh, the contribution of women to their household food supply and nutritional status — the study seeks to assess. The research is emphasizing onto improve the understanding of the important contribution of women in household and valuing their potential role on food security and nutrition in existing status. Improvement of the household food security refers to the expanding availability and accessibility of nutritional food on sustainable basis. In this regard this study has indicated that women in rural, play a crucial role in improving their household food security, as they contribute to food production, enhance dietary quality and consumption diversity. Agricultural production unit (farm, home garden and livestock products) with supplemental resources (processed and preserved food items) and substitute resources (fishing and wild food products) represent the available resources for the household food consumption in rural areas. Along with others off-farm income generating activities (making handicrafts items) and other possible income sources (old woman honorees, pension, ornaments, remittance from migrants, and savings sources) provide household with income to afford foods. In developing countries, rural women play different roles in guaranteeing food security for their households and communities. Women are usually responsible for growing and preparing most of the food consumed in the home and raising small livestock, which provides protein. Rural women also carry out most home food processing, which ensures a diverse diet, minimizes losses and provides marketable products. Women are more likely to spend their incomes on food and children's needs when a woman controls the household budget. Women, therefore, play a decisive role in food security, dietary diversity that's covered good nutrition. But having an adequate supply of food does not automatically translate in to the adequate levels of nutrition. So, efforts to improve food safety must take into account existing gender roles in the food chain, training for women in production, nutrition and decision making aspect can make an immediate contribution to household in food assurance which ensure nutrition and good health.
\end{abstract}

Key words: Empowering women, food production, nutrition, decision making. 